Syed M.A. Raza MD, Robert W. Masters MD, Appa R. Vasireddy MD, Elemer K. Zsigmond MD

\title{
Haemodynamic stability with midazolam- sufentanil analgesia in cardiac surgical patients
}

Since the administration of both diazepam and midazolam are claimed to cause adverse haemodynamic effects following fenianyl or sufentanil intravenous injection, we evaluated the effectiveness and safety of the reverse sequence, (midazolamsufentanil) on haemedynamic variables, adequacy of analyesia. amnesia and recovery in 15 adult patients undergoing coronary artery surgery (with a mean \pm SEM ejection fraction of $0.4 \mathrm{I} \pm$ 0.031 . Affer routine premedication, midazolam $0.14 \pm 0.01 \mathrm{mg}$. $\mathrm{kg}^{-1} \mathrm{IV}$ was given over one min followed $5 \mathrm{~min}$ later by sufentanil in incremental $N$ doses of $1.5 \mu \mathrm{g} \cdot \mathrm{kg}^{-1}$ to a total pre-intubation dose of $4.0-5.0 \mu \mathrm{g} \cdot \mathrm{kg}^{-1}$ injected in 10 min. One minute after the initial dose of sufentanil, pancuronium 0.1 $\mathrm{mg} \cdot \mathrm{kg}^{-1} \mathrm{IV}$ was given in 30 seconds. The incremental doses of sufentanil were based on a greater than 15 per cent increase in rate-pressure product. The mean dose of sufentanil before cardiopulmonary bypass was $9.6 \pm 2.1 \mu \mathrm{g} \cdot \mathrm{kg}^{-1}$ and $13.9 \pm 1.3$ $\mu \mathrm{g} \cdot \mathrm{kg}^{-1}$ for the entire procedure. A significant decrease in systolic and diastolic blood pressures occurred after midazolam administration which was sustained until sternotomy. A significant reduction in systemic vascular resistance occurred following midazolam. Sufentanil reduced the left ventricular strokework index. Tracheal insubation, skin incision and sternotomy elicited no adver se haemadynamic responses. Adequate analge. sia, complete ammesia and early recovery of wakefulness were observed.

\section{Key words}

HYPNOTICS, BENZODIAZEPINES: midaZolam; ANALGESICS, NARCOTIC: sufentanil; SURGERY: cardiac; BLOOD PRESSURE: drug effects.

From the Department of Anesthesiology, The University of Illinois College of Medicine at Chicago, Chicago, Illinois.

Address correspondence to: $\mathrm{Dr}$. Elemer $\mathrm{K}$. Zsigmond, Department of Anesthesiology, The University of Illinois College of Medicine at Chicago, Suite 3200 West, 1740 West Taylor Street, Chicago, Illinois 60612.

This study was conducted at the West Side Veterans Administration Hospital, Chicago, Illinois 60612. The opinions expressed in this paper in no way represent those of the United States Armed Forces or the Veterans Administration.
Diazepam has been used as a safe sleep-inducing agent in patients undergoing cardiac catheterization and cardioversion, ${ }^{1.2}$ but thrombophlebitis, its inadequate hypnotic potency and its long half-life were drawbacks not shared by its water soluble congener, midazolam. ${ }^{3}$ Studies by Fragen et al. ${ }^{4}$ in cardiac patients showed haemodynarnic stability after IV midazolam. On the contrary, both diazepam and midazolam have, when combined with morphine ${ }^{5}$ or fentanyl, ${ }^{6-8}$ been claimed to cause adverse haemodynamic changes in patients undergoing cardiac surgery. Since no reports are available on similar adverse interaction of midazolam with sufentanil, the haemodynamic effects of a midazolam-sufentanil induction sequence in cardiac patients were evaluated.

\section{Methods}

Fifteen patients scheduled to undergo elective aortocoronary artery bypass graft (CABG) surgery were studied. Patients were excluded who had a history of drug habituation or addiction, psychiatric treatment, or allergic reactions to narcotic-analgesic drugs. Patjents who were undergoing emergency surgery or who were minors or prisoners, were also excluded. The patients were entered into the study at random. Written informed consent, as required by the Institutional Research Review Board, was obtained prior to the study. Fourtcen paticnts were male and one female. Mean \pm SEM age was $62.5 \pm 2.1 \mathrm{yr}$ (range 51 to 80), mean weight was $75.4 \pm 2.8 \mathrm{~kg}$, and mean height was $172 \pm 1.4 \mathrm{~cm}$, with a mean BSA of 1.91 $\pm 0.03 \mathrm{~m}^{2}$. Patients were maintained on $\beta$-adrenergic blockers or calcium channel blockers until the timc of anaesthetic induction. The moming digoxin dose was withheld. The mean ejection-fraction was $0.41 \pm 0.03$ (0.31-0.57).

The night prior to surgery, the patients received a benzodiazepine hypnotic, usually triazolam $0.25 \mathrm{mg} \mathrm{PO}$ for sleep. For preoperative preparations each patient received diazepam $0.15 \mathrm{mg} \cdot \mathrm{kg}^{-1} \mathrm{PO}$ and morphine sulfate $0.15 \mathrm{mg} \cdot \mathrm{kg}^{-1}$ IM 60 minutes prior to induction. In addition, six patients also received $0.2-0.4 \mathrm{mg}$ scopolamine IM solely by chance, since one of the investigators routinely uses it in the preoperative medication. 


\section{Monitoring}

In the preoperative preparation area, an intravenous line was established. An arterial cannula was inserted into a radial artery under local anaesthesia. A balloon-tipped, Swan-Ganz pulmonary artery catheter was placed into the pulmonary artery through an introducer previously inserted into the right internal jugular vein. ECG lead II and $V_{5}$ and non-invasive blood pressure (Dinamap) monitoring were continued in the preoperative preparation area until the patients wcre transferred to the operating room. In the OR, direct arterial systemic pressure, pulmonary artery pressure and ECG were recorded on a multichannel monitor linked to a computer terminal. Oxygen saturation. was continuously measured by an oximeter to maintain $>$ 95 per cent saturation. Exhaled $\mathrm{CO}_{2}$ level was displayed and continually recorded by a capnograph in order to assure that a $\mathrm{CO}_{2}$ partial pressure of $35-45 \mathrm{mmHg}$ was maintained. Tidal volume and ventilatory rate were recorded by a respirometer. Blood gases were determined at each blood sampling and if needed. Cardiac output was determined by thermodilution with a cardiac output computer in triplicate.

Haemodynamic data were determined and calculated at the following times before and throughout anaesthesia and surgery.

I Pre-induction: before IV midazolam administration;

2 Post-midazolam but pre-sufentanil: before sufentanil IV or $5 \mathrm{~min}$ after the start of midazolam IV injection;

3 Post-sufentanil but pre-intubation: 5 min after sufentanil and pancuronium IV injection;

4 Post-intubation: 5 min after intubation but before surgical incision;

5 Pre-stenotomy: $10 \mathrm{~min}$ after surgical incision;

6 Post-sternotomy: $10 \mathrm{~min}$ after sternotomy:

7 Pre-bypass: immediately before the start of cardiopulmonary bypass;

8 Post-bypass: after the termination of cardiopulmonary bypass;

9 At the end of surgical procedure

Haemodynamic parameters evaluated were:

- Heart rate (HR)

- Systolic systemic blood pressure: $\left(\mathrm{BP}_{\mathrm{s}}\right) \mathrm{mmHg}$

- Diastolic systemic blood pressure: $\left(B P_{d}\right) m_{m g}$

- Pulmonary artery systolic blood pressure: $\left(\mathrm{PAP}_{\mathrm{s}}\right)$ $\mathrm{mmHg}$

- Pulmonary artery diastolic blood pressure: $\left(\mathrm{PAP}_{\mathrm{d}}\right)$ $\mathrm{mmHg}$

- Pulmonary artery wedge pressure: $\left(\mathrm{PAP}_{\mathrm{w}}\right) \mathrm{mmHg}$

- Central venous pressure (CVP): $\mathrm{cmH}_{2} \mathrm{O}$

- Cardiac output (CO): $\mathrm{L}^{-\mathrm{min}^{-1}}$

The following haemodynamic data were calculated:

- Cardiac index (CI): L $\cdot \mathrm{min}^{-1} \cdot \mathrm{m}^{-2}$

- Stroke volume (SV): m]
- Stroke index (SI): $\mathrm{ml} \cdot \mathrm{m}^{-2}$

- Left ventricular stroke work index (LVSWI): $\mathrm{g} \cdot \mathrm{m} \cdot \mathrm{m}^{-2}$

- Right ventricular stroke work index (RVSWI); $\mathrm{g}-\mathrm{m} \cdot \mathrm{m}^{-2}$

- Systemic vascular resistance (SVR): dynes $\cdot \mathrm{sec} \cdot \mathrm{cm}^{-5}$

- Pulmonary vascular resistance (PVR): dynes $\mathrm{sec} \cdot \mathrm{cm}^{-5}$

- Rate pressure product (RPP): HR $\times \mathrm{BP}_{\mathrm{s}}$

\section{Anaesthetic management}

Midazolam in a mean \pm SEM dose of $0.14 \pm 0.01 \mathrm{mg} \cdot \mathrm{kg}^{-1}$ was given IV over a one-minule interval to the patients spontancously breathing 100 per cent $\mathrm{O}_{2}$. Five minutcs after the end of midazolam injection, incremental doses of $1.5 \mu \mathrm{g} \cdot \mathrm{kg}^{-1}$ sufentanil were given. The total of sufentanil dose was $4.0-5.0 \mu \mathrm{g} \cdot \mathrm{kg}^{-1}$ up to the time of intubation. One minute after the initial dose of sufentanil, pancuron. ium $0.1 \mathrm{mg} \cdot \mathrm{kg}^{-1}$ IV was given. After the development of complete muscle relaxation, tracheal intubation was carried out without spraying the vocal cords with a local anaesthetic. After confirming the correct position of the endotracheal tube, the administration of 100 per cent oxygen or oxygen in air was continued at an $\mathrm{FIO}_{2}$ to maintain $>95$ oxygen saturation. None of the patients received $\mathrm{N}_{2} \mathrm{O}$. Additional incremental doses of 0.6 $\mu \mathrm{g} \cdot \mathrm{kg}^{-1}$ of sufentanil were given based on a greater than 15 per cent increase in RPP. Additional doses of midazolam were injected when eye-signs and clinical evidence of sympathetic activity showed light planes of anaesthesia. Intermittent doses of pancuronium were given throughout anaesthesia when required based on the response of the thumb to ulnar nerve stimulation. No patient jeceived an IV infusion of vasopressors and/or vasodilator drug, ß-blockers or Ca-channel blockers intravenously throughout the study until cardiopulmonary bypass.

During the postoperative period, the following were recorded: times to recovery of spontaneous respiration, to wakefulness and to the first analgesic administration, adequacy of intraoperative amnesia, and postoperative analgesia. On postoperative interviews, the patients were asked to answer yes or no to the following questions: Were you pleased with anaesthesia? Did you feel any pain or discomfort during anaesthesia and surgery? Can you recall any events or conversations during surgery"? Would you object to receiving this anaesthetic technique again?

\section{Data analysis}

The haemodynamic paramelers were evaluated for the change from the baseline at each sampling time during the procedure, using the ANOVA-program. Statistica! significance was defined at $p \leq 0.05$. All values are expressed as mean \pm SEM. 
TABLE Haemodynamic data

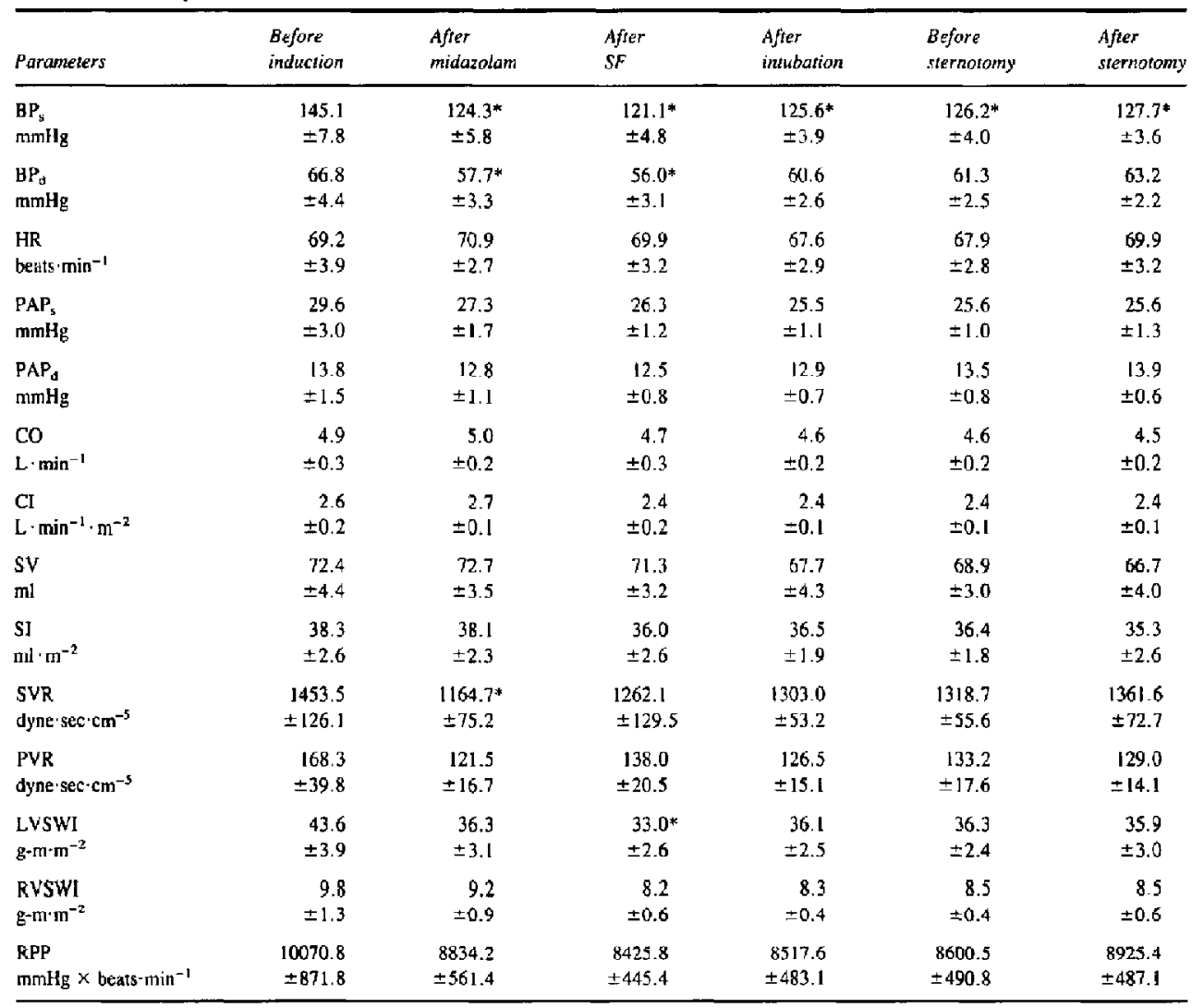

$*_{p}<0.05$. For abbreviations, see Methods.

\section{Results}

Intravenous injection of midazolam per se caused significant reductions in $\mathrm{BP}_{\mathrm{S}}, \mathrm{BP}_{\mathrm{d}}$ and $\mathrm{SVR}$, but no concomitant changes in other directly measured and calculated haemodynamic variables (Table and Figures 1-4).

Injection of incremental doses of sufentanil alone totaling a mean dose of $4.5 \pm 1.2 \mu \mathrm{g} \cdot \mathrm{kg}^{-1}$ for induction and $9.6 \pm 2.1 \mu \mathrm{g} \cdot \mathrm{kg}^{-1}$ before cardiopulmonary bypass caused a decrease in LVSWI after induction but before intubation (Table) but no other significant changes in haemodynamic variables.

The only change in haemodynamic variables caused by intubation was a moderate non-significant increase in $\mathrm{BP}_{\mathrm{s}}$. Nor were HR, SVR, PVR, BP, CO, Cl, SV, SI significantly altered by intubation (Figures 1-4).

Following sternotomy, no statistically significant changes in haemodynamic variables were observed as compared to pre-stemotony or to the pre-induction values.

Throughout anaesthesia and surgery, no other changes in haemodynamic variables were observed until completion of study before the start of cardiopulmonary bypass (Table). The total dose of sufentanil was 13.9 \pm 1.3 $\mu \mathrm{g} \cdot \mathrm{kg}^{-1}$ for the entire procedure. No ECG changes representing ischaemia occurred in any of the patients. No myocardial infarct or pulmonary oedema was observed during the study period before cardiopulmonary-bypass.

Recovery from anaesthesia was uneventful. The mean duration of anaesthesia was $300.0 \pm 14.3 \mathrm{~min}$. The mean time interval from the end of anaesthesia to recovery of wakefulness was $150.0 \pm 35.4 \mathrm{~min}$. The mean time interval from end of anaesthesia to spontaneous ventila- 


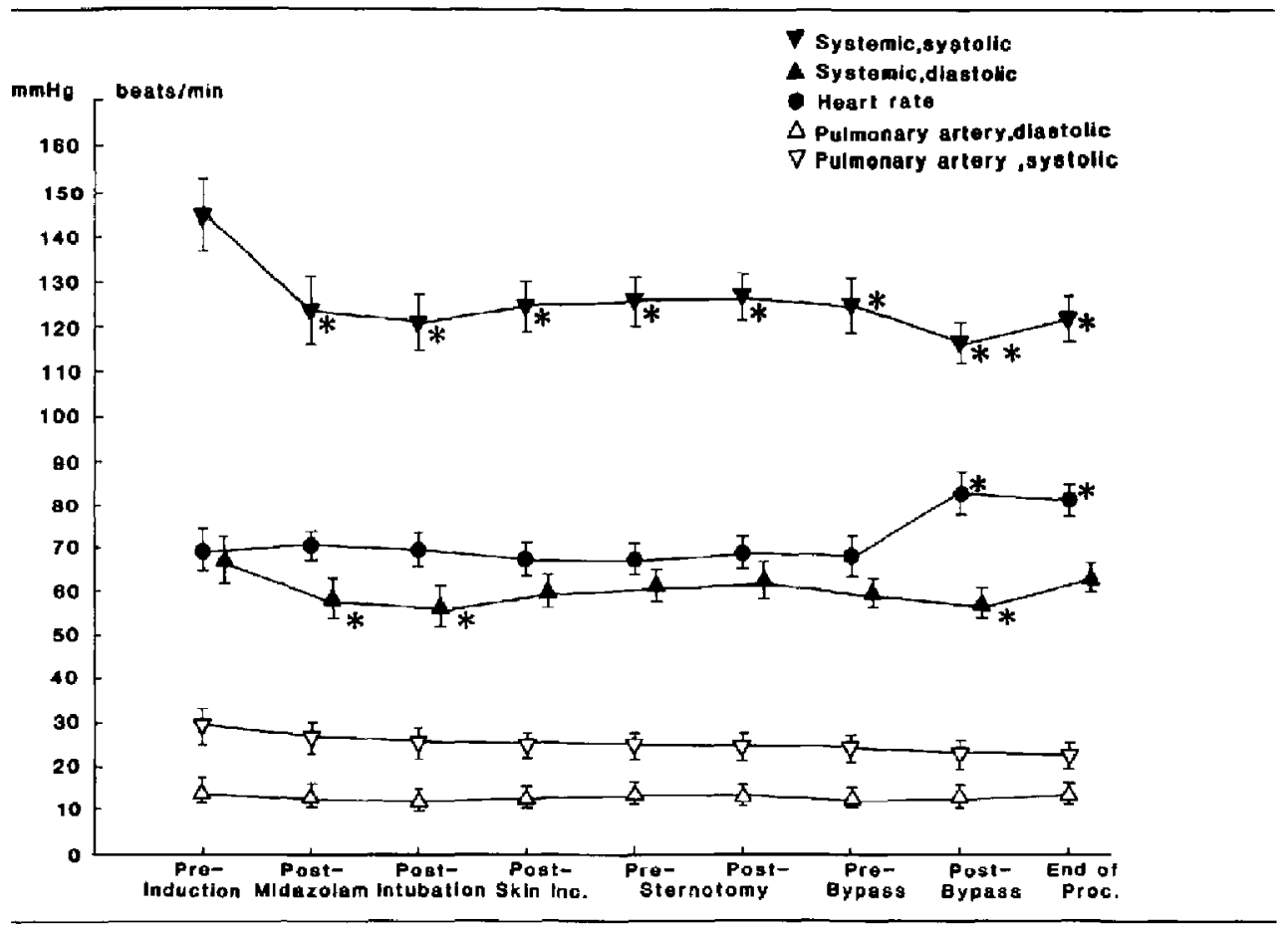

FIGURE 1 Systolic and diastolic systemic blood pressures, hean ratc, and pulmonary anerial pressures, during midazolam-sufentanil analgesia (mean \pm SEM) (** $<0.05 ; * * p<0.01)$.

tion was $966.0 \pm 46.3 \mathrm{~min}$. The mean time interval from the end of anaesthesia to the first reçuired analgesic dose was $120.0 \pm 30.0 \mathrm{~min}$. On postoperative interyiew, all patients were pleased with their anaesthesia. No patient had recall of pain or any events or conversations during anaesthesia and surgery ( 100 per cent amnesia) and none objected to receiving this anaesthetic technique again.

\section{Discussion}

This is the first report on the successful use of midazolamsufentanil for both induction and maintenance of amnesiaanalgesia in patients with coronary artery disease. Our assumption that midazolam and sufentanil induction sequence causes no adverse but rather beneficial haemodynamic changes in patients scheduled to undergo cardiac surgery is substantiated by our results. The reduction in $\mathrm{BP}_{\mathrm{s}}$ (Figure 1) and RPP (Tablc) after midazolam paired with the reduction of SVR (Figure 3 ) was likely to result in reduction of the oxygen demand of the heart muscles.
Indeed, the reduced LVSWI (Figure 4) is further proof for this contention, although actual measurernents on myocardial oxygen uptake were not carried out.

The dose of midazolam used in these cardiac patients was moderate, a sleep-inducing dose of $0.14 \pm 0.01$ $\mathrm{mg} \cdot \mathrm{kg}^{-1}$. Slow careful titration of the minimum effective dose might have contributed to the haemodynamic stability reported. In contrast to the findings of several investigators, $7,9,10$ we observed no sudden decrease in BP or a compensatory tachycardia, which are reflections of the autonomic circulatory response to a sudden decrease in SVR. Some investigator's blamed splanchnic pooling of blood as a cause of hypotension, especially in water depleted hypovolaemic cardiac patients. ${ }^{8}$ Recently this assumption received further proof in experiments in dogs. "Our results confirm the findings of several investigators ${ }^{4,12-14}$ who observed no significant decreases in systemic blood pressures following midazolam in cardiac patients, having received no fentanyl or fentanyl derivatives prior to midazolam. 


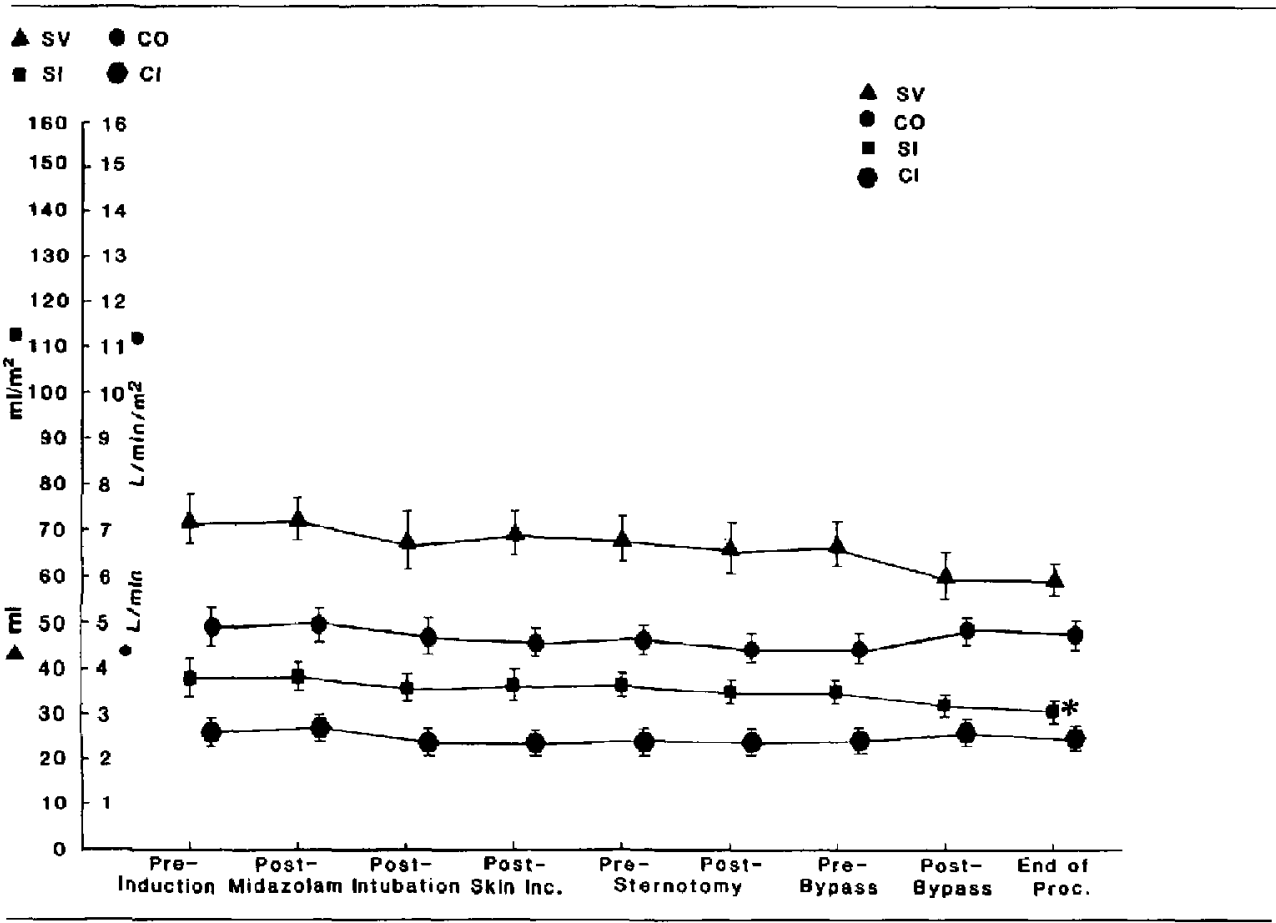

FIGURE 2 Cardiac oulput and index, stroke volume and stroke volume index, during midazolam-sufencanil analgesia (mean $\pm S E M)\left({ }^{*} p<0.05\right)$.

The adverse haemodynamic effects of midazolam following the use of high doses of fentanyl anaesthesia for CABG operation by Heikkilä et a ${ }^{8}$ can be explained by their induction sequence. First, they administered 15 $\mu \mathrm{g} \cdot \mathrm{kg}^{-1}$ of pancuronium for prevention of fentanylinduced truncal rigidity. Then the IV infusion of 75 $\mu \mathrm{g} \cdot \mathrm{kg}^{-1}$ of fentanyl was completed in five minutes. This was followed by $0.15 \mathrm{mg} \cdot \mathrm{kg}^{-1}$ midazolam, the drug studied. Evidently, midazolam was injected at a point when fentanyl still had been exerting its haemodynamic effects. Corsequently, the experimental set-up did not allow the evaluation of the effect of midazolam alone on haemodynamics as even Heikkilä et al. ${ }^{8}$ admitted. Therefore, no conclusion as to the haemodynamic stability following IV midazolam in cardiac patients can be drawn from their studies. Moreover, the lack of reduction of $\mathrm{Cl}$ or SI found (Figure 2) and also reported by Heikkilä t $_{\text {al }}{ }^{8}$ is further proof of the lack of myocardial depressant effect of midazolam even after high doses of fentanyl.

The doses of sufentanil used in our study could be considered as low or moderate doses for both induction and maintenance of analgesia for cardiac surgery. The administration of sufentanil alone following midazolam injection was not associated with any significant haemodynamic changes except for a decrease in LVSWT (Figures 1-4). The slow incremental dosing might have contributed to the favourable results, although the contribution of midazolam to the haemodynamic stability cannot be underemphasized. The stabilizing effect of benzodiazepines on the limbic autonomic centres, thereby reduction of narcotic requirements in neuroleptanaesthesia, is wel] recognized. is

Stressful events such as tracheal intubation, skin incision and sternotomy caused no adverse haemodynamic changes in our patients (Figures 1-4). RPP (Table), LVSWI, RVSWI (Figure 4) and acid-base balance remained unchanged following tracheal intubation, skin incision and sternotomy (Figures $1-2$ ). These events may elicit hypertension, tachycardia and increased catecholamine levels that in cardiac patients, in turn, may precipitate myocardial infarction and fatal cardiac atrhythmias. Although in our cardiac patients there was a blockade of autonomic responses to stressars, the safety of our technique ought to be confirmed in a larger series of 


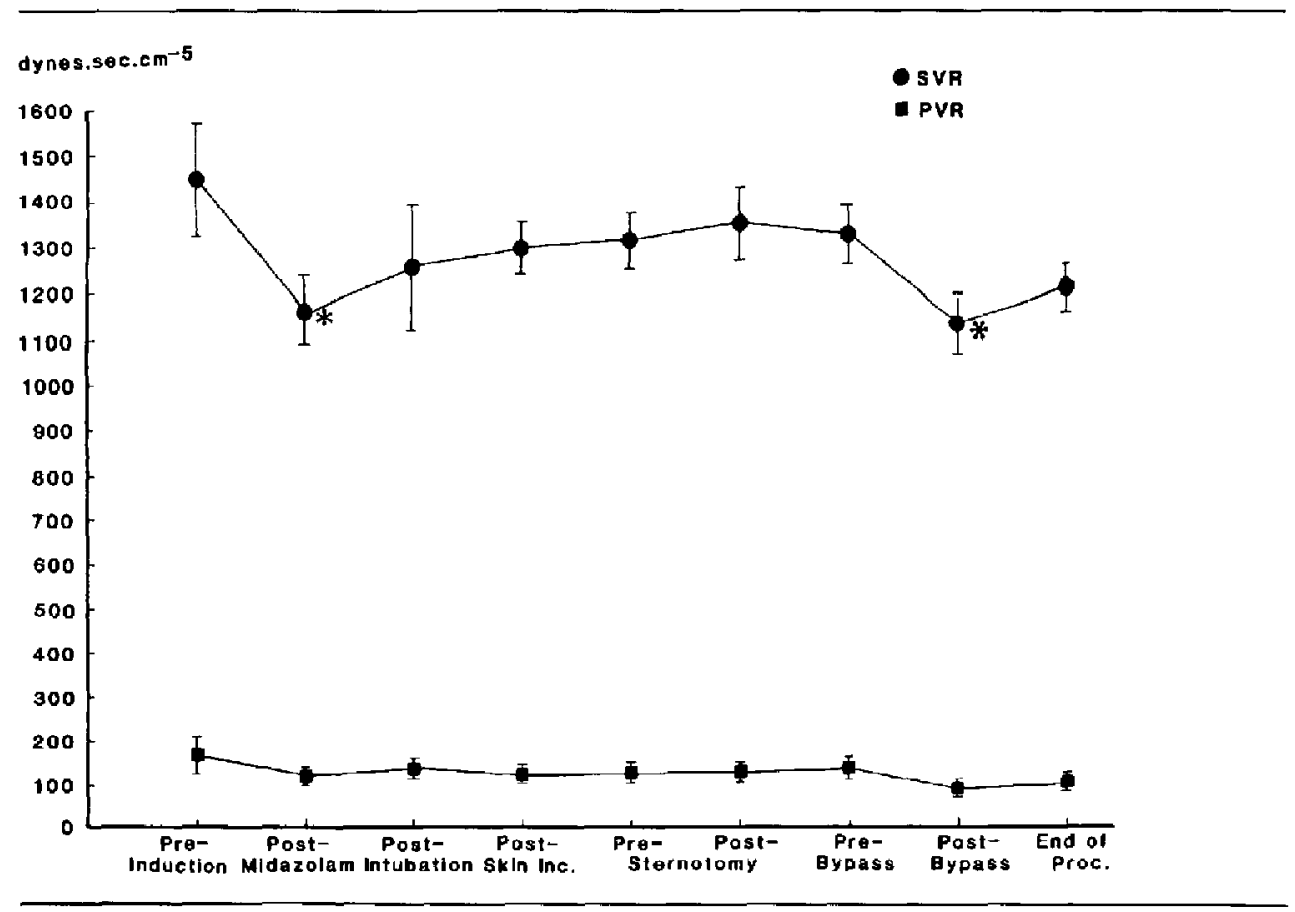

FIGURE 3 Systemic and pulmonary yascular resistance, during midazolam-sufentanil analgesia (mean \pm SEM) $\left({ }^{*} p<0.05\right)$.

patients induced and maintained with midazolam and sufentanil.

The safety of a midazolam-sufentanil anaesthetic induction sequence for induction followed by maintenance of analgesia with sufentanil $-\mathrm{O}_{2}$ is also confirmed by the lack of adverse occurrences intraoperatively in these patients, such as hypo- or hypertension, brady-or tachycardia, arrhythmias, ST-segment changes, pulmonary oedema, and myocardial infarction. Therefore, no vasoactive drugs, inotropic agents or $\beta$-blockers were needcd throughout the course of anaesthesia from induction to cardiopulmonary bypass except for the routine nitroglycerin IV infusion. No recall of pain or any unpleasant experiences were reported in our patients on postoperative interviews. Postoperative analgesia lasting for two hours was another major advantage of our technique. Postoperative return of wakefulness was prompt. The return of spontaneous ventilation was prolonged. This should be taken into consideration in the selection of this anaesthetic technique in patients who are not to be kept on the ventilator for several hours postoperatively, as is routinely done with cardiae patients.
In conclusion, midazolam-sufentanil-pancuronium- $\mathrm{O}_{2}$ induction/intubation sequence caused no adverse haemodynamic changes in cardiac patients in the doses and sequence utilized in our study. Tracheal intubation, skin incision and sternotomy, the most stressful events, elicited no adverse haenodynamic effects. Adequate pain relief, lack of recall of pain or other intraoperative events, the patient's satisfaction and good operating conditions were provided by this anaesthetic technique.

\section{Acknowledgments}

This study was conducted from November 1986 until December 1986 at the West Side Veterans Administration Hospital. We want to express our gratitude to $\mathrm{N}$. A. Silverman, MD and P. J. DelNido, MD for allowing their patients to participate in our study and for their helpful advice curing these investigations. The generous support of the Research Fund of the Department of Anesthesiology made this study possible. We are cspecially indebted to Judy Colvin for the typing and editing of this manuscript and to Vincent J. Collins, MD for his review of this manuscript. 


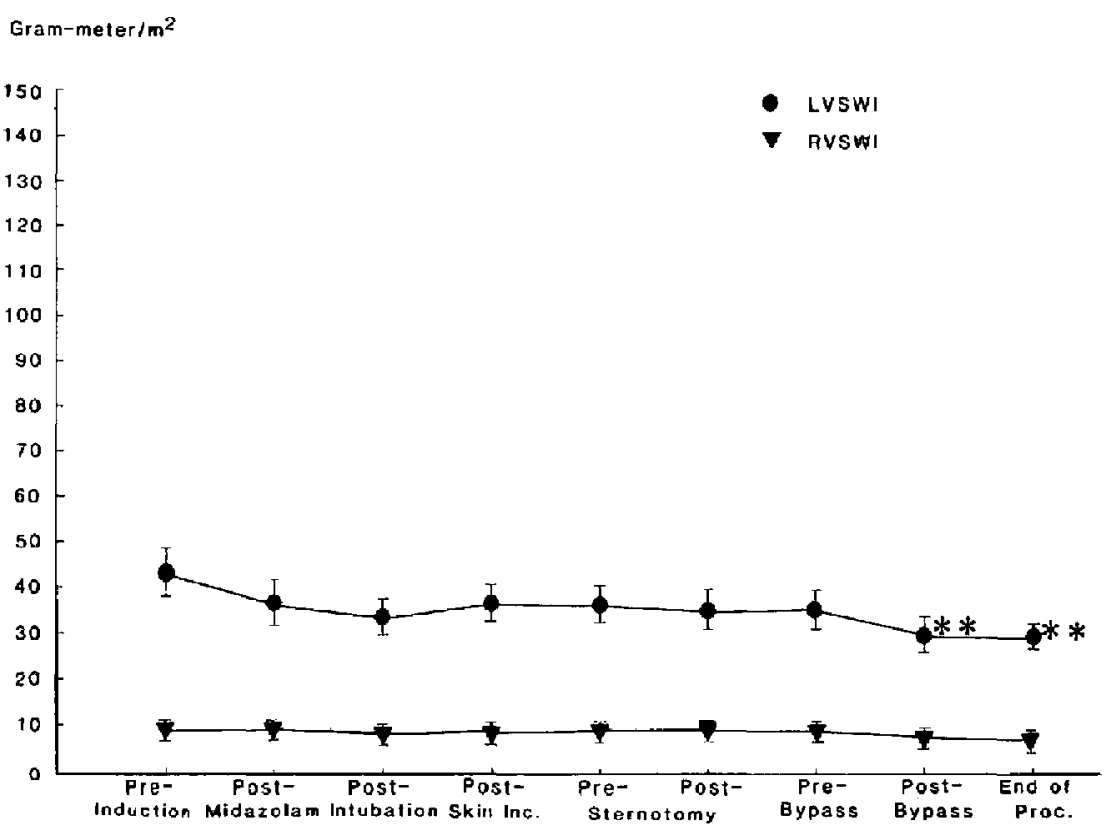

FIGURE 4 Left and right ventricular stroke work indexes, during midazolam-sufentanil analgesia (mean \pm SEM) $\left({ }^{* *} p<0.01\right)$.

\section{References}

1 Dundee JW, Keilly SR. Dinzepan. In. Clarke RS (Ed). Newer intravenous anesthetics. Boston, USA: International Anesthesia Clinics Series, Little Brown \& Co., 1969; 7; 109.

2 Rao S, Sherbaniuk RW, Prasad K, Lee SJK, Sproule $B J$. Cardiopulmonary cffects of diazepam. Clin Pharmacol Therap 1973; 14: 182.

3 Pieri L. Schoffiner $R$, Scherschlicht $R$ et al. Pharmacology of Midazolam. Arzneim Forsch Drug Res 1981; 31 (11): Nr 12a 2180-2201.

4 Fragen $R J$, Meyers $S N$, Barresi $V$, Caldwell $N J$. Hemodynamic effects of midazolam in cardiac patients. Anesthesiology 1979; 51 : \$103.

5 Hoar PF, Nelsan NT, Mangano DT, Bainton CR, Hickey $R F$. Adrenergic response to morphine-diazepam anesthesia for myocardial revascularization. Anesth Analg $1981 ; 60: 406$.

6 Stanley $T H$, Webster $L R$. Anesthet ic requirements and cardiovascular effects of fentanyl-oxygen and fentanyldiazepam-oxygen anesthesia in man. Anesth Analg 1978; 57: 411-6.

7 Tomicheck RC, Rosow CE, Philbin DM, Moss F, Teplick
$R S$, Schneider $R C$. Diazepam-fentany] interactionhemodynamic and hormonal effects in coronary artery surgery. Anesth Analg 1983; 62: 881-4.

8 Heikkilä $H$, Jalorzen J, Arola $M$, Kano J, Laaksonen $V$. Midazolam as adjunct to high-dose fentanyl anaesthesia for coronary artery bypass grafting operation. Acta Anaesthesiol Scand 1984; 28: 683-9.

9 Samuelson PN, Reves JG, Kouchoukos NT; Smith LR, Dole $K M$. Hemodynamic responses to anesthetic induction with midazolam or diazepam in patients with ischemic heart disease. Anesth Analg 1981; 60: 802-9.

10 Reves JG, Kissin I, Fournier S. Negative inotropic effects of midazolam. Anesthesiology 1984; 60: 517-8.

11 Adams P, Geiman S, Reves JG, Greenblatt DJ, Alvis JM, Bradley $E$. Midazolam pharmacodynamics and pharmacokinetics in dogs during acute hypovolemia. Anesth Analg 1985; 64: 186.

12 Reves JG, Samuelson FN, Lewis $\$$. Midazolam maleare induction in patients with ischaemic heart discase: haemodynamic observations. Can Anaesth Soc J 1979; 26: 402-9.

13 Samuelson PN, Reves JG. Smith $L R$, Kouchoukos NT. Midazolam versus diazepam: different effects on 
systemic vascular resistance. Arzneim Forsch Drug

Res 1981; 31: 2268-9.

14 Morel $D$, Forster A, Gardaz JP, Suter PM, Gemperle $M$. Comparative haemodynamic and respiratory effects of midazolam and flunitrazepam as induction agents in cardiac surgery. Arzneim Forsch Drug Res 1981; 31: 2264-5.

15 DeCastro PJ, Andrieu S, Dubois A, Van Heuneghem L. Étude du midazolam comme inducteur, correcteur et potentialisateur d'une anesthésie analgesique à base d'alfentanil. Arzneim Forsch Drug Res 1981; 31: $2251-4$.

\section{Résumé}

On a évalue les effects et la sécurité de la séquence midazolamsufentanil sur les variables hémodynamiques, te degré d'analgesie, l'amnésie, et le réveil chez quinze patents adultes subissant une chirurgie coronarienne. Après une prémédication de routine le midazolam $0.14 \pm 0.01 \mathrm{mg} \cdot \mathrm{kg}^{-1}$ par voie intraveineuse a été administré en une minute suivi cing minutes plus tard par le sufentanil a des doses de $1.5 \mu \mathrm{g} \cdot \mathrm{kg}^{-1}$ pour ure dose totale pré-intubation de $4.0-5.0 \mu \mathrm{g} \cdot \mathrm{kg}^{-1}$ injectée en dix minutes. Une minute après la dose initiale de sufentanil, du pancuronium $0.1 \mathrm{mg} \cdot \mathrm{kg}^{-1}$ a été administré en 30 secondes. Les doses additionnelles du sufentanil étaient basées sum une augmentation supérieure a 15 pour cen dans le produit pressionfréguence. La dose moyenne de sufentanil avant la CEC était de $9.6 \pm 2.1 \mu \mathrm{g} \cdot \mathrm{kg}^{-1}$ et $13.9 \pm 1.3 \mu \mathrm{g} \cdot \mathrm{kg}^{-1}$ pour la totalité de la procédure. Une diminution significative des pressions systoli. ques et diastoliques est survenue après administration de midazolam et ceci fut soutenu jusqu'à la sternotomie. Une diminution significative de la résistance vasculaire systémique est survenue après midazolam. Le sufentanil a diminué le travail d'éjection indexé du ventricude gauche. L'intubation trachéale, l'incision cutané et la sternotomie n'ont pas amené de réaction hémodynamique. Une amalgésie adéquate, une amrésie complète et un réveil précoce furent observés. 